\title{
Hageman factor, high molecular weight kininogen, and prekallikrein in chronic liver disease
}

\author{
C CORDOVA, F VIOLI, C ALESSANDRI, D FERRO, M SALIOLA, F BALSANO \\ From the Institute of Clinical Medicine I, University of Rome "La Sapienza", Italy
}

SUMMARY The activities of Hageman factor, high molecular weight kininogen (HMWK), and prekallikrein were studied in patients who had chronic active hepatitis and cirrhosis. Serum HMWK and prekallikrein activities were decreased in chronic active hepatitis and cirrhosis, but Hageman factor activity was low in cirrhosis only. The reduction of prekallikrein, HMWK, and Hageman factor was dependent on the degree of liver failure. Similar prekallikrein values were found in serum samples, activated or not, with an excess of Hageman factor and HMWK, which suggests that the decrease of prekallikrein in liver disease is not influenced by the simultaneous decrease of Hageman factor and HMWK.

Prekallikrein, a protein synthesised by liver cells, ${ }^{1}$ is an activator of intrinsic coagulation and fibrinolytic pathways. ${ }^{23} \mathrm{~A}$ recent investigation showed that prekallikrein plasma activity is a very sensitive marker of liver failure, making it a potentially useful indicator of liver insufficiency. ${ }^{4}$

The functional assay of prekallikrein requires Hageman factor and high molecular weight kininogen (HMWK), two constituents of the initial coagulation phase that can be reduced in liver failure. ${ }^{5-7}$ In fact, at least $25 \%$ of normal Hageman factor activity is necessary for prekallikrein to be converted into kallikrein; HMWK seems to be a cofactor in the initial rate of kallikrein formation. ${ }^{5-7}$ As low values of prekallikrein in patients with cirrhosis could be due to low Hageman factor and HMWK activities, we studied the relation between prekallikrein, Hageman factor and HMWK in patients affected by chronic liver disease to evaluate the in vitro influence of Hageman factor and HMWK on prekallikrein activation. Analysis of prekallikrein activity was performed with and without a clotting activator containing an excess of Hageman factor and HMWK.

\section{Material and methods}

The study was carried out on $\mathbf{3 0}$ patients with chronic liver disease: 10 had chronic active hepatitis (six men, four women; aged 27-58 years); and 20 had cirrhosis
(13 men, seven women; aged 32-73 years). Chronic active hepatitis was diagnosed by needle liver biopsy, according to the recommendations of the International Committee. ${ }^{8}$ Cirrhosis was diagnosed by liver biopsy in 11 patients and on clinical data and laboratory tests in nine patients. These included the following criteria: hepatosplenomegaly; ascites or jaundice, or both; spider naevi; signs of liver failure (low concentrations of serum albumin and vitamin $\mathrm{K}$ dependent factors) and an increase of aminotransferases and the gamma band in serum protein electrophoretic patterns. Liver needle biopsy was not performed in these nine patients as their serum biochemistry was severely abnormal and the biopsy risks were too high. Patients were considered to be decompensated if they showed at least two of the following signs: ascites; hepatic encephalopathy; prothrombin test (Quick) $<40 \%$; serum albumin $<30 \mathrm{~g} / \mathrm{l}$; serum bilirubin $>68.4 \mu \mathrm{mol} / \mathrm{l}^{9}$ Nineteen patients (seven with chronic active hepatitis and 12 with cirrhosis) had antibodies for hepatitis B virus; eight with cirrhosis had clinical histories of alcoholism, and three patients were thought to be affected by autoimmune chronic active hepatitis. All studies were made with the patients' informed consent in accordance with the Helsinki Declaration.

\section{COAGULATION STUDY}

Blood samples were taken from fasting subjects, mixed with $0.13 \mathrm{~mol} / 1$ sodium citrate in a ratio of $9: 1$, and centrifuged for 15 minutes at $2000 \mathrm{~g}$. 
Table 1 Normotest, prekallikrein, Hageman factor, and high molecular weight kininogen (HMWK) values in healthy subjects, those with chronic active hepatitis, patients with liver cirrhosis, those with compensated liver cirrhosis, and those with decompensated liver cirrhosis

\begin{tabular}{|c|c|c|c|c|c|c|}
\hline & $\begin{array}{l}\text { Healthy } \\
\text { subjects }\end{array}$ & $\begin{array}{l}\text { Chronic } \\
\text { active } \\
\text { hepatitis }\end{array}$ & $\begin{array}{l}\text { Liver } \\
\text { cirrhosis }\end{array}$ & $\begin{array}{l}\text { Compensated } \\
\text { liver } \\
\text { cirrhosis }\end{array}$ & & $\begin{array}{l}\text { Decompensated } \\
\text { liver } \\
\text { cirrhosis }\end{array}$ \\
\hline \multirow{2}{*}{$\begin{array}{l}\text { Normotest } \\
\text { Prekallikrein } \\
\text { Hageman factor } \\
\text { High molecular } \\
\quad \text { weight kininogen }\end{array}$} & $\begin{array}{l}91 \cdot 5(7 \cdot 5) \\
91 \cdot 6(12 \cdot 5) \\
96 \quad(19)\end{array}$ & $\begin{array}{l}66(16 \cdot 9) \dagger \\
62(17 \cdot 9) \ddagger \\
80(27)\end{array}$ & $\begin{array}{lr}39 \cdot 6 & (15) \ddagger \\
32 & (20) \ddagger \\
42 & (11) \ddagger\end{array}$ & $\begin{array}{l}49.4(15.2) \\
42.8(12 \cdot 6) \\
50.4(10 \cdot 3)\end{array}$ & $\begin{array}{l}\leftrightarrow \\
\leftrightarrow\end{array}$ & $\begin{array}{l}25.6(5.6) \ddagger \\
16.7(7.8) \ddagger \\
32.8(3.8) \ddagger\end{array}$ \\
\hline & $108 \quad(16)$ & $88(19)^{*}$ & $52 \quad(12) \ddagger$ & $60.2(11.9)$ & $\leftrightarrow$ & $44 \cdot 6(6) \ddagger$ \\
\hline
\end{tabular}

${ }^{*} \mathrm{p}<0.025 ; \mathrm{tp}<0.01 ; \ddagger \mathrm{p}<0.001$.

Prothrombin activity was performed by Normotest (Nyegaard and $\mathrm{Co}$ ), according to the manufacturer's instructions. Schnitger and Gross coagulometer was used for evaluating Normotest.

The prekallikrein activity assay comprised $100 \mu \mathrm{l}$ diluted plasma ( $50 \mu \mathrm{l}$ plasma plus $600 \mu \mathrm{l} 50 \mathrm{mM}$ Tris buffer, pH 7.8), $800 \mu$ l diluted Cephotest (nine parts Tris buffer plus one part Cephotest; Nyegaard and Co), or $800 \mu \mathrm{l}$ diluted prekallikrein activator (nine parts Tris buffer plus one part prekallikrein activator, a mixture of ellagic acid, cephalin, and plasma containing Hageman factor and HMWK (Kabi Diagnostics), which were incubated for three minutes at $37^{\circ} \mathrm{C}$ and then added to $0.6 \mathrm{mM}$ substrate S-2302 (Kabi Diagnostics). The reaction mixture was incubated at $37^{\circ} \mathrm{C}$ and stopped after one minute with $50 \%$ acetic acid. Prekallikrein activity was read at $405 \mathrm{~nm}$ on a Beckman spectrophotometer and calculated by a standard curve performed by scaled dilution of normal pooled plasma. ${ }^{10}$

Plasma activities of Hageman factor and HMWK were assayed by a modification of a prothrombin time using plasma congenitally deficient in Hageman factor (Boehringer Biochemia) and HMWK (Nyegaard and $\mathrm{Co}$ ) plasma. ${ }^{7}$ Clotting time was measured with a Schnitger and Gross coagulometer, and the percentage activities of Hageman factor and HMWK were calculated from a calibration curve performed as above.

Twenty healthy subjects matched for age were studied as controls. The mean and SD of the results and Student's $t$ test were calculated.

\section{Results}

Low values of prekallikrein and HMWK were observed in chronic active hepatitis, while Hageman factor activity was within the normal range (table 1). Decreased values of prekallikrein and HMWK and low Hageman factor activity were seen in cirrhosis, where the amount by which these proteins were decreased was related to the degree of liver failure. In fact, decompensated patients with cirrhosis had lower prekallikrein, Hageman factor, and HMWK values than did compensated patients. Similar prekallikrein values were observed independent of whether or not the clotting activator contained Hageman factor and HMWK (table 2). This was also evident in decompensated patients with cirrhosis who had very low prekallikrein values. In this subgroup the lowest Hageman factor and HMWK values were $27 \%$ and $39 \%$, respectively.

\section{Discussion}

Previous investigations have shown that prekallikrein plasma activity is decreased in patients with chronic liver disease, depending on the degree of liver failure. ${ }^{1}$ Prekallikrein values were correlated with those of Normotest, which determines vitamin $\mathrm{K}$ dependent factor activity and is considered to be a good marker of liver failure. ${ }^{1} \mathrm{~A}$ more recent investigation suggested that prekallikrein could be a good prognostic indicator of liver failure as prekallikrein values of patients who had not survived with cirrhosis were

Table 2 Prekallikrein values in samples activated or not with an excess of Hageman factor and high molecular weight kininogen (prekallikrein + activator) in cases of chronic active hepatitis, compensated liver cirrhosis, decompensated liver cirrhosis, and liver cirrhosis

\begin{tabular}{lllll}
\hline & $\begin{array}{l}\text { Chronic active } \\
\text { hepatitis }\end{array}$ & $\begin{array}{l}\text { Compensated } \\
\text { liver cirrhosis }\end{array}$ & $\begin{array}{l}\text { Decompensated } \\
\text { liver cirrhosis }\end{array}$ & $\begin{array}{l}\text { Liver } \\
\text { cirrhosis }\end{array}$ \\
\hline $\begin{array}{l}\text { Prekallikrein } \\
\begin{array}{l}\text { Prekallikrein }+ \\
\text { activator }\end{array}\end{array}$ & $62(17 \cdot 9)$ & $42 \cdot 8(12 \cdot 6)$ & $16 \cdot 7(7 \cdot 8)$ & $32(20)$ \\
\hline
\end{tabular}


appreciably lower than those of survivors. ${ }^{4}$ This agrees with a previous finding that prekallikrein plasma activity reflects residual functional liver cell mass. ${ }^{11}$ Very low prekallikrein values, however, such as those observed in decompensated cirrhosis could be due to a concomitant lowering of Hageman factor or HMWK, or both, two proteins active in the initial phase of the intrinsic coagulation pathway that are necessary for in vitro prekallikrein activation. ${ }^{56} \mathrm{Hag}-$ eman factor and HMWF activities are reduced in chronic liver disease, but not so low as to affect prekallikrein assay; and this is supported by finding similar prekallikrein values independently of whether or not the prekallikrein activator contained an excess of Hageman factor and HMWF.

The obvious conclusion of this study is that in cirrhosis, particularly in decompensated cirrhosis, where the lowest Hageman factor and HMWF values can be found, prekallikrein activity does not seem to be influenced by Hageman factor and HMWF activity values. This is probably due to the limited reduction of Hageman factor and HMWF, which never reach values below $25 \%$. The low plasma activity of prekallikrein found in decompensated cirrhosis should, therefore, be regarded as a direct consequence of liver protein synthesis failure, provided that other conditions known to affect prekallikrein activity, such as endotoxaemia or intravascular coagulopathy, are excluded. ${ }^{1213}$

\section{References}

1 Cordova C, Musca A, Violi F, et al. Prekallikrein behaviour in chronic active hepatitis and in cirrhotic patients. Haemostasis 1984;14:218-22.

2 Kluft C. Determination of prekallikrein in human plasma: optimal conditions for activating prekallikrein. J Lab Clin Med 1978;91:83-95.
3 Friberger P, Eriksson E, Gustavsson S, Claeson G. Determination of prekallikrein in plasma by means of a chromogenic tripeptide substrate for plasma kallikrein. In: Fujii S, Mariya $\mathrm{H}$, Suguki T, eds. Kinins II biochemistry: pathophysiology and clinical aspects. New York: Plenum Publishing Corporation, 1979:67-84.

4 Cordova C, Violi F, Alessandri C, et al. Prekallikrein and factor VII as prognostic indexes of liver failure. Am J Clin Pathol (in press).

5 Colman RW, Mattler L, Sherry S. Studies on the prekallikrein (kallikreinogen)-kallikrein enzyme system of human plasma. II. Evidence relating the kaolin-activated arginine esterase to plasma kallikrein. J Clin Invest 1969;48:23-32.

6 Liu CY, Scott CF, Bagdasarian A, Pierce JV, Kaplan AP, Colman W. Potentiation of the function of Hageman factor fragments by high molecular weight kininogen. $J$ Clin Invest 1977;60:7-17.

7 Saito H, Goldsmith G, Waldmann R. Fitzgerald factor (high molecular weight kininogen) clotting activity in human plasma in health and disease in various animal plasmas. Blood 1976;48:941-7.

8 Fogarty International Center Proceedings. Nomenclature, diagnostic criteria and diagnostic methodology for diseases of the liver and biliary tract. Washington: US Government Printing Office, 1976:9.

9 Franco D, Durandy Y, Deporte A, Bismuth H. Upper gastrointestinal haemorrhage in hepatic cirrhosis: causes and relation to hepatic failure and stress. Lancet 1977; i:218-20.

10 Stornorken H, Baklund A, Gallimore M, Ritland S. Chromogenic substrate assay of plasma prekallikrein. Haemostasis 1978;7:68-75.

11 Violi F, Alessandri C, Saliola M, Caputo V, Bonavita MS, Balsano F. Correlation between hepatic blood flow and coagulation indices in chronic active hepatitis and liver cirrhosis patients. Haemostasis 1985;15:210-4.

12 Robinson JA, Kladnycky ML, Loeb HS, Racic MR, Gunnar RM. Endotoxin, prekallikrein, complement and systemic vascular resistance. Am J Med 1975;59:61-7.

13 Cordova C, Violi F, Alessandri C, Musca A, Balsano F. Low doses of calcium-heparin in liver cirrhosis. Thromb Haemost 1985;54:551.

Requests for reprints to: Professor F Violi, Institute of Clinical Medicine I, University of Rome "La Sapienza", Policlinico Umberto I, 00161 Rome, Italy. 